\title{
REVIEW
}

\section{Environmental Problem Analysis and Policy Recommendations on Pacific Northwest Salmon}

\author{
Jingjing Tao* \\ Department of Agricultural Economics, Purdue University, West Lafayette Indiana, 47907, United States
}

\section{ARTICLE INFO}

Article history

Received: 24 May 2021

Accepted: 18 June 2021

Published Online: 10 August 2021

Keywords:

Environmental problems

Pacific northwest salmon

Policy proposal

Political analysis

\begin{abstract}
Environmental issues are becoming hot topics nowadays. As the steps of industrialization and urbanization expand, the conflict between economic development and environmental protection appears to intensify and catch people's eyes more frequently, from the disappearing Amazon rainforest to the pollution of Mississippi River. Over the past few months, the news of one species, salmon, dying out in the northwestern part of the United States drew our team's attention. In this paper, I would like to present my research on Pacific Northwest salmon from the perspectives of problem statement, policy proposal, and political analysis.
\end{abstract}

\section{Introduction}

In the Pacific Northwest, salmon were threatened with extinction. An article called Northwest's Salmon Population May Be Running Out of Time, written by Fazio ${ }^{[1]}$ briefly stated this emergent issue and explained how several factors caused the large reduction of salmon, which included toxic pollution, artificial barriers and unusual warmth. It was the growing human population and rapid development that made it hard for salmon to adapt to the changing environment quickly enough. Under this circumstance, their survival was at stake. After only four or five generations, this species was estimated to die out.

Neglecting the negative externalities for the society, a great number of transportation construction and energy infrastructures were established along the shoreline. The man-made pro-development facilities made a harmful influence on salmon's habitat and the related pollutants also exacerbated salmon's living circumstances. As can be seen, the absence of policy intervention has led to the disastrous condition of salmon population. Therefore, an effective policy is required. Under this circumstance, policy intervention is necessary for the salmon aggravating problem.

A promising solution is being proposed by Congressman Mike Simpson ${ }^{[2]}$. He aims to restore the Lower Snake River and salmons through the "removal of four federal dams, funding for the Yakima Basin Integrated Plan, incentives to remove select fish-blocking dams in the Columbia Basin, and increasing tourism and recreation opportunities" ${ }^{[3]}$. From my perspective, it is an appropri-

*Corresponding Author:

Jingjing Tao,

Department of Agricultural Economics, Purdue University, West Lafayette Indiana, 47907, United States;

Email:2673629363@qq.com 
ate response since most detrimental human behaviors are originated from the existing dams. The biggest advantage of the policy is that directly dealing with the source of the issue, together with additional stimulus to the economy are very likely to contribute to a success. Ideally speaking, the joined efforts can boost the recovery of salmons at a fast speed. However, the disadvantage of the policy is the violation of some factories' interests in that area, because of which the policy implementation may encounter the opposition from these groups. Comparing this trade-off to the huge benefits of salmon restoration, the weaknesses fall behind. A similar successful dam removal policy existed elsewhere, for example, the removal of Edwards Dam in 1999 , letting the species there rebound and recover.

\section{Discussion on Problem Mechanisms and Potential Resolutions}

The policy that I believe would be most beneficial to achieve the goal of saving Pacific Northwest salmon is the removal of specific dams and the simultaneous addition of water treatment facilities to the water flow. The primary appeal of this policy is the reestablishment of the river's natural flow, which in turn will restore the natural environmental functions and habitats of the surrounding ecosystem that originally supported a larger salmon population. Although dams benefit clean energy production in short-term consideration, the costs of their maintenance and environmental interruption severely outweigh the positive results ${ }^{[4]}$. Dams are detrimental to the microclimates of surrounding areas through major water cycle changes, such as mass evaporation causing temperature fluctuation disruption.

Dams do not solely disrupt the natural temperature fluctuation, however. The unnatural patterns of water movement cause a sensation known as "hungry water"where the flowing water is high energy with little sediment. In turn, this disrupts the chemical composition of the river that gives guiding signals to migrating species, such as birds and other fish going through their biological processes ${ }^{[5]}$. The physical barrier goes further to prevent these natural occurrences, as the physical barrier restricts access to the traditional safe spawning and rearing habitats. Through this series of obstacles, the natural behavioral patterns of native species, specifically salmon, have been disrupted in the interest of human development.

The implementation of water treatment facilities following the natural flow of water will dive even further into supporting the regression of nature back to its original function, providing the necessary aeration and supplement balance to support a major influx of salmon in these bodies of water. According to Clean-Flo ${ }^{[6]}$, as the water cycle changes, the nutrient content of the water will be regulated by certain types of water filters that will reduce the impact of this drastic change on the local bodies of water.

The policy change with the greatest potential for salmon population recovery with the lowest risk factors would be the removal of the four Lower Snake River dams. Although these dams generate electricity, there is a great cost to the natural ecosystems that eliminate the dams as a sustainable energy source if any concern is to be given to the environment. Possible risks associated with this major change create a large fear factor, as the water cycle changes could potentially affect surrounding communities long-term, raise costs of energy production, and alter the availability of aquatic resources for the local consumers.

When comparing the alternatives, I would like to discuss the options available for energy production for the communities that rely heavily on the energy produced by the water-driven generators existing on these dams. As they exist, the costs of the water energy generators are severely imbalanced by the negative costs and effects of their existence. When considering other options, there are multiple alternative clean energy sources, such as windmills or solar power, that have a lower risk factor and less detrimental environmental effects.

Another discussed topic in this policy development was the management of water runoff. The sheer magnitude of a serious project like this is a risk in itself, as the possibility of detrimental effects on the water's already elevated level of pollution is a major concern as the runoff has the potential to collect and sit there. This would be a devastating result to not only the salmon population, but the surrounding communities, ecosystems, and habitats of coexisting species would all suffer the mass destruction of their existence as it is.

Because of this, there is the potential for conflicts in this policy's implementation. These risks include the potential effects on the environment from the deconstruction of these dams, such as changing fish and bird migration patterns and compromising the established function of the natural water cycle of the surrounding environment, which could pose flood risks for the surrounding areas. The removal of these dams will also affect the abilities of these communities, especially considering their use as sources of clean electricity generation. Local areas are rightfully concerned with the possibility of tax increases resulting from this loss of mass energy production. Because of these negative effects that removing the dams could bring to local communities, there is a significant rate of local opposition to this policy. Despite the serious risks and concerns associated with this proposed policy, the potential benefits that the policy could bring outweigh 
the negatives in tenfold.

Although this particular policy regarding the removal of these exact dams has not been played out and attempted before, there is research on similar situations that suggests that this would be a positive option to regenerate the salmon population of the Pacific Northwest. The results of these similar attempts combine to support the idea that this policy correlates with the greatest potential recovery of the salmon slump.

The closest relative example to this policy is the Puget Sound Salmon Recovery projects. The findings of these efforts suggest that, while dams benefit salmon populations in short-term results by providing a sort of rest place in their lifetime and an option for a life-supporting safe habitat, there are methods of supporting the salmon population with long-term sustainability in mind. Through removing these dams, salmon populations will at first lose this safe point, but will eventually revert back to their natural habitats and behavioral patterns as the river returns to its native flow ${ }^{[7]}$. As the current man-made habitat features are removed, the original natural salmon habitats will slowly restructure to the areas that supported their larger population in the first place.

Another consideration to make for the repopulation of salmon in the Pacific Northwest is the function of hatcheries, which take fish eggs and assure their safety in their development. Although these hatcheries are beneficial to the salmon population by creating the ideal artificial environment for salmon in order to breed a larger population at a faster rate, they are also depleting the natural resources necessary to support the local natural ecosystem. However, if necessary, hatcheries are an option that may be considered should the need arise for a major population increase as the immediate result of the dam removal by change in habitat. These hatcheries assure that with the fluctuation in salmon population after the dam removal, there will not be an entire extinction of salmon native to the Pacific Northwest.

Puget Sound salmon recovery efforts also gave insight into what may be a primary concern in this policy's implementation. Throughout the series of efforts, shoreline salmon habitat destruction has been a consistent battle that has yet to reach a sustainable and logical solution. This alone is a large contributor to the depletion of Pacific Northwest salmon population fluctuation, but the removal of dams that add pressure to the shoreline has the potential to allow recovery of these natural safe ecosystems.

Throughout similar policy implementation documented by Puget Sound Partnership ${ }^{[8]}$, the idea of compromise between federal, tribal, state, and local organizations has become an important formative structure in the success of the attempted goal, in this case, the regeneration of the Pacific Northwest salmon population. Although political conflicts influence the belief systems, participation, and goals of each division, these groups, should the policy regarding the dam removal be approved, will be forced to come to a compromise for the betterment of the native environment that supports a large variety of important systems stemming from the original salmon population's survival.

Some of the compromises regarding these divisions include the potential monetary costs of the project itself, the effects on the developed ecosystem that an influx of salmon population growth will have, and the supporting and opposing interest groups or communities behind this policy. These criteria are important to consider and decide before the implementation of this proposed policy, as their conflicts if left unaddressed could potentially ensure the failure of the salmon population recovery, leading to a further detrimental effect on the ecosystems and local communities.

The potential costs lying behind this policy lie primarily in labor, as the dam removal, hatchery development, energy redirection, and changes in irrigation are all full remodeling projects that will require materials, time, effort, and skills. A series of professionals in a wide variety of fields will be required to do a full evaluation, build or remove structures properly, support the local communities and ecosystems in their survival and comfort, and determine the best route of action to benefit the salmon population without compromising the surrounding life or land. The costs of a major change in energy production, as the dam removal also removes water-driven energy generation in a multitude of areas, is also something that will need thoughtful consideration.

Energy production is already a very controversial subject among political and environmental interest groups, and according to Born ${ }^{[9]}$, the removal of this significant source of clean energy will drive the interest of certain groups, whether positively or negatively. For example, energy moguls and urban expansion supporters would be expected to be opposed to the policy, as the removal of these energy generators would be a step backwards from their goals. Alongside them, the local population may potentially advocate against this policy in fear of its effects on the comfort and economic situations of their communities and surrounding areas. In contrast, environmental advocacy groups may be expected to support this policy, as it is designed to fully benefit the natural ecosystem structure of the Pacific Northwest and will restore the habitats that originally supported salmon population with minimal human intervention. 
In the change of the dam removal, however, there is a plethora of environmental change factors to consider in the policy development. As dams change the water cycle by producing a larger standstill body of water, leading to a higher rate of evaporation ${ }^{[9]}$, the removal of such would potentially reduce the rain level by a significant amount. Flooding of local communities, especially as the water cycle is in the process of reregulating itself, is also a considerable factor. Natural predators and prey of the surrounding ecosystem will also experience a major change, which could potentially risk other resources and put other habitats at a similar situational disadvantage in the future.

\section{Policy and Political Analysis on Resolution Proposal}

Though the removal of the four Lower Snake River Dams would restore the salmon population of the region, the main concern of passing this policy is convincing other interest groups that the benefits of this move outweigh the potential problems that could arise from doing so. Obviously, the power provided by the four dams would have to be replaced, which is an expensive process. On top of that, the dams provide a number of other benefits, such as allowing cheap transport of goods via barges, which is a major blow to Idaho's agricultural farmers.

The political aspect of the policy implementation requires not only demonstrating that the policy would work, but that the solution can work with minimal impact to potential affected parties, such as farmers who will need alternatives to transport of goods, local communities, who need the power provided by the dams, and taxpayers, who need justification on why such a plan is important for preserving the local wildlife of Idaho.

The Lower Snake River Dams are federal dams, which means that legislation would have to reach the Federal Government to get the necessary approval for breaching the dams. However, past attempts to receive permission to breach have failed, as several agencies, including the Army Corps of Engineers, the Bureau of Reclamation, and, most importantly, the Bonneville Power Administration, have deemed the ordeal too costly and too taxing on the Northwest power grid.

These parties are relatively neutral when it comes to local wildlife restoration, but their position is heavily affected by technical feasibility of the proposal. If the breaching of the dams were to destroy local irrigation systems, or the power generated by the dams couldn't be replaced. Then they would be less likely to support our legislation and would advise Congress to vote against it. The main focus of our political approach should consider their concerns in our strategy, as they've been a major roadblock to similar legislation in the past.

On top of getting approval from these essential administrations, the policy needs to pass at the congressional level. Alternative solutions to previous legislation have been put in place, such as spilling water over the dams during the spring. However, these alternatives won't create an impactful level of restoration, and will continue to promote reliance on the dams which have caused severe damage to local ecosystems. To reach this level of legislation, we will need to utilize a key actor within Congress.

The most essential key actor to utilize for promoting our policy is United States Congressman Mike Simpson. He represents Idaho's $2^{\text {nd }}$ district and shows great interest in salmon restoration in the region. The Congressman has attended hundreds of meetings on the subject and attempted to bring legislation to the House of Representatives, which failed due to the aforementioned reasons. Congressman Simpson is our best chance at proposing legislation to Congress, which is nearly essential if we have any hope of making our proposal a reality.

At the current moment, similar policies have been extremely popular among environmental groups as well as communities who rely on fishing and tourism for their local economies. Losing the salmon population could potentially destroy tourism and fishing within the region. Another major supporter of the policy is the Shoshone Bannock Tribes, who've seen the drastic decline of salmon in the rivers for decades as a result of the dams. "The fish aren't coming back, nothing is working here", says Nathan Small, a leadership member of the Shoshone Bannock ${ }^{[10]}$. The destruction of the salmon population would tarnish the fishing grounds they've been using throughout their history. It's important to utilize the support of these groups because they represent the communities around these rivers and ecosystems. If their concerns are made apparent and they're encouraged to call their congressperson, more and more support can be gained in Congress and more legislatures would be on board.

On the other side, our largest potential opponents include the Bonneville Power Administration, who need a comprehensive plan to either match or exceed the power output of the dams, and local farmers, who need confirmation that the plan won't damage their irrigation systems or completely hinder current transportation routes. It's absolutely necessary that our political approach includes farmers, as their support is essential to prove that our plan is feasible.

Farmers must be supported by this legislation as they are potentially the most impactful when it comes to public support. Their grievances can be linked to two major concerns, transportation of crops and irrigation. Farmers in 
the region largely rely on barges as a cheap and effective way to transport their crops. These barges rely on the waterways created by the dams in order to traverse the river safely, so breaching the dams could make these waterways difficult to traverse. In recent years, however, barge transport has mostly been on the decline. "Over the past 20 years even grain volume has declined by more than 40 percent ${ }^{\text {"[11] }}$. This means that as barge transport phases out over time, potential externalities involving crop transportation can be avoided.

Another concern from farmers is irrigation, as current irrigation systems rely on the waterways altered by the dams. However, a majority of farmland is inland from the river, and systems that actually utilize the river can be extended via pipes. This may be one of the trickier portions of the proposal since reconstruction of these systems may be required, but the support of local farmers is essential enough to warrant it.

The Bonneville Power Administration manages the electric power market on the Columbia River, which connects to Snake River. As a result, they are the main party that needs convincing in terms of power production. At the current moment, they don't support breaching the dams because, if the region were to replace the energy produced by the lower Snake dams, it would most likely be with a fossil fuel, natural gas" ${ }^{[12]}$. They will require a comprehensive plan that utilizes clean energy.

Alternative energy such as wind and solar isn't something new in the Lower Snake River Valley. Wind farms already have a considerable presence in the region under Puget Sound Energy, the operation created 149 turbines that produces "enough annual electricity to power 70,000 homes, while also contributing jobs and commerce to the local economy" ${ }^{[13]}$. If it is possible to cooperate with the BPA to establish a deadline for more wind farms in the region to match the output of the dams, then they may be convinced to support the recommended proposal.

The nature of policy requires that the political approach should be one of reassurance and assessing who is affected by what. The key actor Mike Simpson must be utilized to present the legislation to Congress and take advantage of his knowledge on the subject, as well as identify where his legislation has failed in the past. The legislation must address the concerns of the potential oppositions. Therefore, the approach should be oriented to address concerns of those parties and organizing them to take the position of saving Pacific Northwest salmon. Last but not least, gaining the support of the local people is vital. There are parties in favor of the legislation already. However, including the needs of skeptics to the resolution proposal, mainly farmers, are necessary as well. If their needs are addressed and their stance on the issue swings in the favor of environmentally friendly, the new supporters will contact their congressperson and create even more supports in the House and the Senate.

\section{Conclusions}

This issue needed to be solved because it was closely related to the local people's lives. Salmon was the vital species for the environment, economy and culture there. Specifically, more than 138 species cannot live without salmon in those food chains, according to Cederholm et al. ${ }^{[14]}$. As an essential link in the pacific northwest region, salmon's absence could lead to a devastating collapse in that ecological system. A worsening environment was obviously not a piece of good news to the residents. In addition, Hagenbuch ${ }^{[15]}$ indicated that the loss of salmon risked around 16,000 unemployment in the commercial and recreational fishing industry. Less salmon would result in fish stock shortage and tourism decline, and these two markets' economies would be damaged consequently. Moreover, salmon played an important role in Native American's culture there, acting as a cultural heritage for indigenous tribes. Galbreath et al. ${ }^{[16]}$ studied the negative impacts of salmon slump to the well-being of tribal peoples, in which salmon fostered their religion and cultural belief. For thousands of years, salmon shaped the lives of the people who have lived here since time immemorial. Moreover, Crozier et al. ${ }^{[17]}$ warned that salmon would become extinct by 2060 and this issue desperately needed immediate actions. There was a market failure at play, due to the tragedy of the commons. Specifically, the ecological habitat of salmon is a common pool, where people there neglected the well-being of society in the pursuit of personal gain. The dams were built out of economic purposes, however at the cost of negative externality towards the environment. Considering all the elements above, the endangered situation of salmon should be taken into consideration at least by the local government.

The decisions and behaviors of governmental actors and interest groups to this issue, namely Pacific Northwest legislators, governors, native American tribes, residents and factory stakeholders are important factors that contribute considerable efforts into the problem, especially during the legitimation and implementation process of the effective policy. An example of potential venue shopping related to this case would be Washington State Recreation and Conservation Office and Idaho Department of Environmental Quality. Both of them are state agencies in Pacific Northwest region of the United States and they are responsible for environmental protection and conservation. To achieve the final goal of saving Pacific Northwest 
salmon, more research and proposals are needed to form useful alliance. I expect the coalition of government environment departments and local residents will be formed because the salmon distinction issue is going to affect the regional economy as well as the life quality of the people. With this alliance structured, the policy can confront less obstacles and impediments.

\section{References}

[1] Fazio, M. (2021). Northwest's Salmon Population may be running out of time. Retrieved from https://www. nytimes.com/2021/01/20/climate/washington-salmon-extinction-climate-change.html.

[2] Creating Certainty and Security for Grain Producers. (2021). U.S. Congressman Mike Simpson - 2nd district of idaho. Retrieved from https://simpson.house.gov/ news/documentsingle.aspx? DocumentID=399175.

[3] Irvin, W. (2021). A bold plan for salmon, clean energy and jobs in the Pacific Northwest. Retrieved from https://www.americanrivers.org/2021/02/a-bold-planfor-salmon-clean-energy-and-jobs-in-the-pacificnorthwest/

[4] Stahl, S. (2017). Dams + climate change = Bad news. Retrieved from https://www.earthlawcenter.org/ blog-entries/2017/12/dams-climate-change-bad-news

[5] Larinier, M. (2001). Environmental issues, dams and fish migration. Retrieved from http://www.fao.org/3/ Y2785E/y2785e03.htm

[6] CLEAN-FLO. (2019). Custom aeration systems and products that work in every type of water body. Retrieved from https://www.clean-flo.com/custom-design-build/

[7] U.S. Fish and Aquatic Conservation. (2021). Atlantic salmon. Retrieved from https://www.fws.gov/ fisheries/fishmigration/atlantic_salmon.html\#: :text $=$ Atlantic $\% 20$ salmon $\% 20$ are $\% 20$ an $\% 20$ anadromous,they\%20grow\%20into\%20an\%20adult

[8] Puget Sound Partnership. (2020). Salmon recovery in Puget sound. Retrieved from https://www.psp.wa.gov/ salmon-recovery-overview.php

[9] Born, S., Field, K., Lander, D., Bendewald, M., Cooper, L., Dittrich, T.M. and Carlson, D.W. (2008). Water resources: Why do we build dams? Retrieved from https://www.teachengineering.org/lessons/view/cub_ dams lesson 01

[10] KPVI News. (2021). Rep. Mike Simpson believes dam removal will restore salmon numbers. Retrieved from www.youtube.com/watch? $=\mathrm{GV} 764 \mathrm{Az} 4 \mathrm{vPY}$

[11] Laughy, L. (2018). Lower Snake River commerce hits all-time low. Retrieved from www.idahorivers. org/newsroom/2018/1/4/2017-lower-snake-river-freight-transportation-review\#: : text=Barges $\% 20$ no\%20longer\%20transport $\% 20 \operatorname{logs}, 15 \% 2$ Dyear $\% 20$ decline $\% 20$ to\%20zero

[12] Federal Caucus. (2016). Lower Snake River Dams power benefits. Retrieved from www.salmonrecovery.gov/home/lower-snake-river-dams-power-benefits\#: :text=The $\% 20$ four $\% 20$ lower $\% 20$ Snake $\% 20$ River,limit\%20its\%20greenhouse \%20gas\%20emissions

[13] PSE Puget Sound Energy. (n.d.). Puget Sound Energy: Lower Snake River wind facility. Retrieved from www.pse.com/pages/facilities/lower-snake-river\#: :tex$\mathrm{t}=$ Completed $\% 20$ in $\% 20$ early $\% 202012 \% 2$ C $\% 20$ Low er,commerce\%20to\%20the\%20local\%20economy

[14] Cederholm, C., Johnson, D., Bilby, R., Dominguez, L., Garrett, A., Graeber, W., Greda, E., Kunze, M., Marcot, B. and Palmisano, J. (2000). Pacific salmon and wildlife-ecological contexts, relationships, and implications for management: Special edition technical report. Olympia, Washington: Washington Department of Fish and Wildlife.

[15] Hagenbuch, B. (2021). Washington state salmon report offers warning to Alaska. Retrieved from https:// www.seafoodsource.com/news/supply-trade/washington-state-salmon-report-offers-warning-to-alaska

[16] Galbreath, P.F., Bisbee Jr, M.A., Dompier, D.W., Kamphaus, C.M. and Newsome, T.H. (2014), "Extirpation and tribal reintroduction of coho salmon to the interior Columbia River basin", Fisheries, 39 (2), 7787.

[17] Crozier, L.G., Burke, B.J., Chasco, B.E., Widener, D.L. and Zabel, R.W. (2021), "Climate change threatens Chinook salmon throughout their life cycle”, Commun. Biol., 4 (1), 222. 